\title{
The preservation of somatic embryos of papaya derived from papaya lateral shoots after being stored in cryopreservation to maintain plant genetic information in the future
}

\author{
DINI HERVANI ${ }^{1, \vartheta}$, DARDA EFENDI, ${ }^{2, \vartheta}$, M. RAHMAD SUHARTANTO², BAMBANG S. PURWOKO² \\ ${ }^{1}$ Program in Plant Breeding and Biotechnology, School of Graduates, Institut Pertanian Bogor. Bogor 16680, West Java, Indonesia. \\ " email: dardaefendi@gmail.com

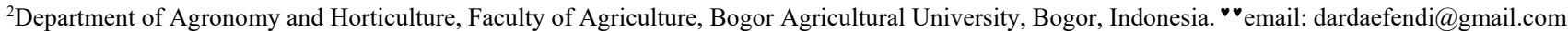

Manuscript received: 1 December 2017. Revision accepted: 2 April 2018.

\begin{abstract}
Hervani D, Efendi D, Suhartanto MR, Purwoko BS. 2018. The preservation of somatic embryos of papaya derived from papaya lateral shoots after being stored in cryopreservation to maintain plant genetic information in the future. Biodiversitas 19: 724729. Germplasm storage of papaya is very important because this plant easily adapts to genetic changes due to environmental conditions and open system pollination, so it is necessary to retain the current genetics resources in order to conserve the genetic information. The storage of the vegetative part of the plant with cryopreservation is expected to retain the plant's genetic information in the future. Cryopreservation is the method for germplasm storage using liquid nitrogen at temperature of $-196^{\circ} \mathrm{C}$ This experiment aimed to obtain the growth ability of papaya lateral shoots to produce somatic embryos after being stored by cryopreservation. The experiment was designed in factorial by Completely Randomized Design with two factors. The first factor was the immersion time duration in PVS2 as cryoprotectant solution with 5 treatments of immersion duration of $0,10,20,30$, and 40 minutes. Second factor was culture medium for cultivated the lateral shoot which was added with plant growth regulators such as BA (benzyl adenine) and NAA (naphthalene acetic acid) at levels of $0,1,2,3$, and $4 \mathrm{mg} \mathrm{l}-1$, respectively. The results showed that the immersion of lateral shoot in cryoprotectants for 10 and 20 minutes gave the better plantlet survival rate after discharge from liquid nitrogen, while the treatment of culture media had not been significant difference.
\end{abstract}

Keywords: Cryoprotectant, liquid nitrogen, Sukma varieties $\square$

Abbreviations: PVS2: Plant Vitrification Solution 2, DMSO: dimethylsulfoxide, BA: benzyl adenine and NAA naphthalene acetic acid

\section{INTRODUCTION}

Germplasm is living genetic resources such as seeds or other living tissue, from which new plants can be grown. Conservation of germplasm is very important, one of its functions is as a genetic source for the scientific development of plant assembly in the future. Traditionally, plant genetic resources are usually planted only in the field as collection of gardens. This storage of genetic material has a risk of losing a sufficiently high genetic source due to abiotic and biotic stress. Other storage methods are usually by storing parts of the genetic material in the laboratory or the gene bank. In general, the management of laboratory storage is costly. It must also have many experts, and may have the risk of genetic changes because of continuous subcultures on genetic material stored in tissue culture. One of technique to store germplasm for long periods of time and also can minimize laboratory costs and the occurrence of genetic alteration is cryopreservation. Cryopreservation is the method for germplasm storage using liquid nitrogen at temperature of $-196^{\circ} \mathrm{C}$ as storage media. The cryopreservation technique enables to halt the cell division and metabolic processes of stored cells, tissues or organs, so that plant material can be stored for a very long time without any changes or somaclonal variation (Fang et al. 2004).
The fast freezing cryopreservation is one of the cryopreservation method used in this study. Fast freezing cryopreservation is done by immersing the planting material in cryoprotectants followed by quick freezing process by dipping the planting material directly into liquid nitrogen (Engelmann 2000). The genetic material, which will be stored usually has high water content, therefore in the cryopreservation process, the dehydration process with the cryoprotectants in the form of glucose, glycerol, ethylene glycol and dimethylsulfoxide is done to remove water in the cells. Water released through the dehydration process is conducted to avoid the formation of ice crystals, which can cause cell damage and cell death (Engelmann 2004).

Germplasm storage of papaya is very important because the genetic changes of papaya plant is easily changed due to environmental conditions and open system pollination. Whereas, papaya has a high genetic diversity so that efforts to maintain the genetic information is necessary to avoid genetic degradation of germplasm in the future. Germplasm storage of papaya in the form of seeds often has problems because the resistance level of papaya seeds to dry is mostly intermediates so that seeds are only able to be stored no longer than 6 months. The genetic source that similar to the parents is the vegetative part of the plant 
(clonal material).In papaya plants, lateral shoots can be utilized to develop plants which have the same characteristic as the parents.

Sukma papaya (Sweet Sukabumi) (Carica papaya L. var Sukma), is one of papaya varieties that can grow well in the lowlands to medium with an altitude of 100-700 meters above sea level. The development of this papaya is in cooperation with the Department of Agriculture Food Plant Sukabumi District, West Java, Indonesia with Tropical Horticulture Study Center, Bogor Agricultural University, Indonesia, with the lead breeder is Prof. Sriani Sujiprihati. This papaya has been released as a new variety by the Minister of Agriculture on October 12, 2009. Sukma papaya represents papaya with large fruit size, weights about 2436-3136 grams per fruit, oval-shaped, large-sized fruit with a diameter of about $13 \mathrm{~cm}$. The productivity of this variety is 50 -70 tons per hectare per year. Sukma papaya has red meat color in flesh, when it is riped, the skin color is yellow at the tip of the fruit (Sobir 2009). Oktaviani (2012) has reported that three varieties of papaya (Sukma, Calina, and Carisya) exposed to low-temperature treatments showed that Sukma papaya is categorized as intermediate varieties of seeds with the germination value $<50 \%$ after a storage period of three months.

Sukma varieties with intermediate seed cannot be stored for a long period of time, so that efforts to store the germplasm for genetic resources in the future is necessary. Therefore, the objective of this study was to know the growth ability of papaya lateral shoots to produce somatic embryos after being stored by cryopreservation so it is expected that the storage of this clonal material becomes the genetic information of the parent that can be maintained in the future.

\section{MATERIALS AND METHODS}

\section{Study area and materials}

This experiment has been carried out at the Tissue Culture Laboratory 1, Faculty of Agriculture, Bogor Agricultural University, Bogor, Indonesia in September 2016 until October 2017.

The material used in this research was the papaya lateral shoots (Carica papaya L. var. Sukma) derived from the papaya crop in the university farm of Bogor Agricultural University, Tajur, Bogor. Other materials were MS medium, dimethylsulfoxide (DMSO), glycerol, ethylene glycol, benzyl adenine (BA), naphthalene acetic acid (NAA), liquid nitrogen and sterile distilled water. Tools were used included laminar air flow cabinet, ovens, scales, autoclave, aluminum foil, paper stencils, hand sprayer, jam jars, and other tools.

\section{Procedures}

\section{Lateral shoots sterilization}

In this experiment, the 2 -week olds papaya lateral shoots grown along the papaya parent tree which previously had been cut off at the top were used as plant materials. The grown lateral shoots were subsequently cut and placed in a cool box to keep the freshness. They were then washed under running water for 60 minutes for early sterilization. They were then immersed with dithane ${ }^{@}$ and banlate $^{\circledR}$ as fungicide and bactericidal solution for 30 minutes, then rinsed under running water. Subsequently, the lateral shoots were immersed in the several levels of Clorox concentration, i.e., a 30\% Clorox solution for five minutes, $15 \%$ Clorox solution for fifteen minutes which were then rinsed two times with sterile aquadest. Afterward, they were immersed in $10 \%$ Clorox solution for ten minutes and rinsed once with sterile aquadest, followed by immersion with 5\% Clorox solution for five minutes, rinsed two times with sterile aquadest. The lateral shoots were then immersed with Rifampicin ${ }^{\circledR}$ as antiseptic by diluting $450 \mathrm{mg}$ of Rifampicin ${ }^{\circledR}$ in $200 \mathrm{ml}$ sterile aquadest for 5 minutes. The sterilized lateral shoots were then immersed in a cryoprotectant solution called PVS2 for 0 , $10,20,30$, and 40 minutes in $-10^{\circ} \mathrm{C}$ as an explant protector before being put into liquid nitrogen.

\section{Cryopreservation procedures}

The lateral shoots that have been immersed in sterile cryoprotectants PVS2, which was previously autoclaved at temperature of $121^{\circ} \mathrm{C}$ and pressure of 17.5 psi for 20 minutes The composition of Plant Vitrification Solution 2 (PVS2) followed Sakai et al. (1991), i.e., 30\% glycerol, $15 \%$ dimethylsulfoxide (DMSO), and $15 \%$ ethylene glycol (EG). Afterward, the lateral shoots were then wrapped in 3 layers with aluminum foil and were stored in liquid nitrogen for at least two hours for cryopreservation storage. The lateral shoots were then removed and thawed in the water bath at $40^{\circ} \mathrm{C}$ for three minutes. The lateral shoots were then incubated in a liquid MS medium for 30 minutes to remove cryoprotectant remnants. The submerged explants were subsequently sterilized with 5\% Clorox for five minutes, followed by rinsing with sterile aquadest three times, and the last, explants soaked with antibiotics (Rifampicin ${ }^{\circledR}$ ) for one minute. The sterilized explants were planted in the treatment medium, and the growth was observed.

\section{Planting explants}

Lateral shoot explants were planted in the laminar air flow cabinet. Each explant originated from a side shoot growings along the papaya trees that the top of it has been cut off. The length of explants was approximately $5-10$ mm. Explants were put in the treatment medium using tweezers. Each culture bottle of treatment was filled with three explants and 10 replication. Then the culture bottle was covered with plastic, then was tied with a rubber band and lastly in wrapping to avoid contamination. $\square$

\section{Observation}

Parameters observed in this study were, i.e., (i) The age of proembryo somatic or callus formation (days), (ii) The average of explant survivals, (iii) The average of explant contamination, (iv) The direction of explants growth, (v) The phenotypical appearances of the cross-section of papaya lateral shoots observed on microscope. The sample of the lateral shoots immersed with cryoprotectants and its 
performances after it was stored in the liquid nitrogen was made in cross-sectional preparations for comparison. $\square$

\section{Data analysis}

The study was designed as completely randomized design with two factors, The first factor was the different time interval treatment of immersion in cryoprotectant solution called Plant Vitrification Solution 2 (PVS2). The interval treatment consisted of five different times including $0,10,20,30$, and 40 minutes. The second factor was a side shoot planting medium added with plant growth regulators (ZPT), i.e., BA (benzyl adenine) and NAA (naphthalene acetic acid) at level concentrations of $0,1,2$, 3 , and $4 \mathrm{mg} \mathrm{l}^{-1}$, respectively. The treatment was replicated 10 times, and each treatment unit on the bottle contained 3 explants. The observational data were tested for diversity by Duncan's Multiple Range Test (DMRT) test analysis at the level confidence of $5 \%$.

\section{RESULTS AND DISCUSSION}

\section{The cross-section of papaya lateral shoots on microscopic observation}

The cross-section of the papaya lateral shoots in each treatment, showed different cell conditions. On fresh lateral shoots (Figure 1.A) there are many chloroplasts on palisade which are dominated by green and intercellular walls neatly lined up. On the lateral shoots that have been immersed in a cryoprotectant (Figure 1.B), visible green color within the cell was reduced, while at the lateral shoots that have been out of the liquid nitrogen (Figure 1.C-D) contents of the cells showed a little green because the content of cell had been replaced with cryoprotectant.

\section{Average of explant survival and contamination}

From two different factors used in this study, showed that the average of explant survival and contaminated explants were significantly different only in single-factor, i.e., immersion in cryoprotectants. In Figure 2.A, it appears that the lateral shoot explants had a different response influenced by the duration of immersion of explants in cryoprotectant. Immersion explants for 20 minutes gave the high average of explant survival while the explants immersed for 40 minutes had no one survive. Interestingly, the observation of contamination also showed that explants immersed in cryoprotectant solution for 20 minutes had low contamination results, while the immersion of explants for 40 minutes showed that overall explants were contaminated. Moreover, results showed that explants were not affected by a wide variety of treatment medium, which could be observed from the survival rate of explants in most of treatment media (Figure 2.B).

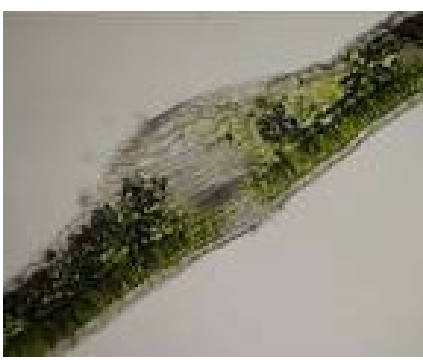

A

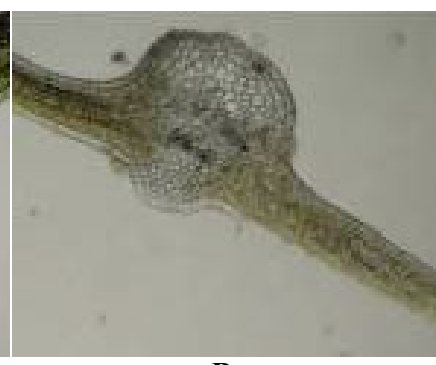

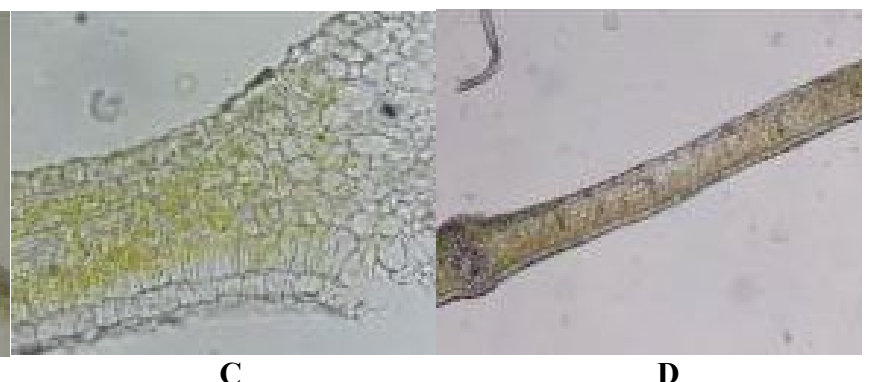

C (i) Fresh

Figure 1. Cross section of papaya lateral shoot with an enlarged binocular microscope $40 \mathrm{x} 10$ brand Olympus type CX23:
lateral shoot, B. Lateral shoot after immersed on cryoprotectant, C. and D. Lateral shoot after coming out from liquid nitrogen

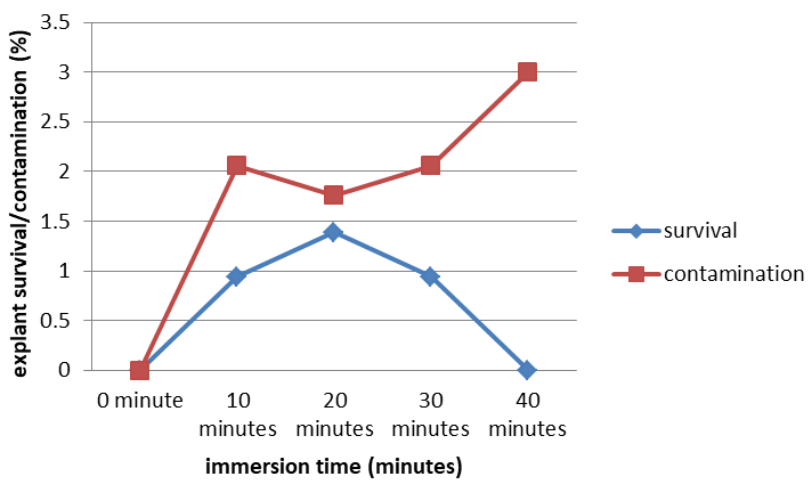

Figure 2.A. The effect of different time of cryopreservation immersion on the average of explant survival and contamination

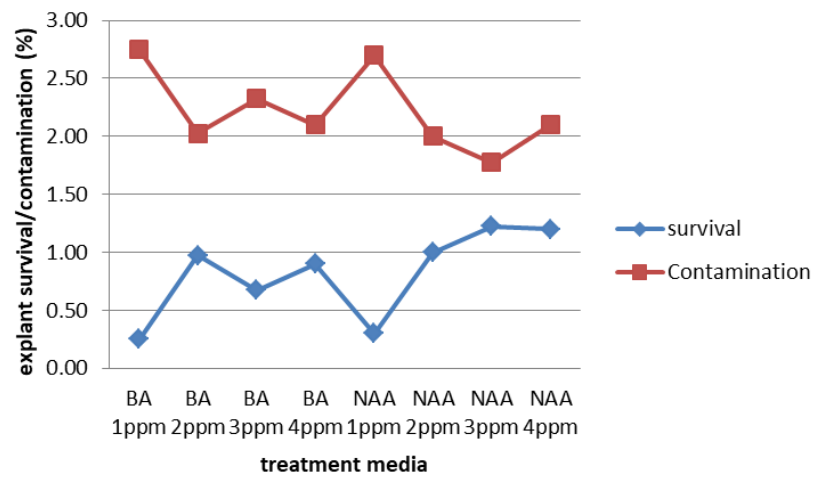

Figure 2.B. The effect of cryopreservation on different media treatments toward the average of the explant survival and contamination 
In Table 1, it can be seen that the immersion of explants for 10 minutes in MS medium supplemented with 2 ppm NAA gave the better survival of explants. However, the immersion of explants for 20 minutes in medium MS supplemented with 4 ppm BA and 4 ppm NAA gave best results. Immersion of explants for 30 and 40 minutes resulted in low survival of explant, even at immersed for 40 minutes no explants were able to grow in all planting mediums. $\square$

Table 2 showed that contamination of explants was low after explants were immersed in cryoprotectant for 10 minutes and grown in MS medium supplemented with 2 ppm NAA. The same results were also shown in explants immersed with cryoprotectant for 20 minutes and grown in medium 4 ppm NAA and 4 ppm BA, respectively. Immersion of explants for 40 minutes gave the contamination results of all used treatment media.

\section{The induction of proembryo somatic or callus formation and the direction growth of callus}

In this experiment, the observation of the first callus or somatic embryo was first seen on the fifteen days after explants planted on the medium (Figure 3 ). Figure 3 shows that lateral shoot as an explants which has been removed from liquid nitrogen with immersion of explants on cryoprotectant for 20 minutes and planted on MS medium supplemented with 4 ppm NAA was able to survive and grew embryogenic callus with the characteristics of compact, opaque, with the growth was relatively slow and in complex structure on MS medium. From the other results, it also showed that sole explant was being able to survive and to form callus directly (Figure 4), so that the further growth of callus to be plantlets and the correlation between treated media and immersion time in callus growth could not be defined clearly.

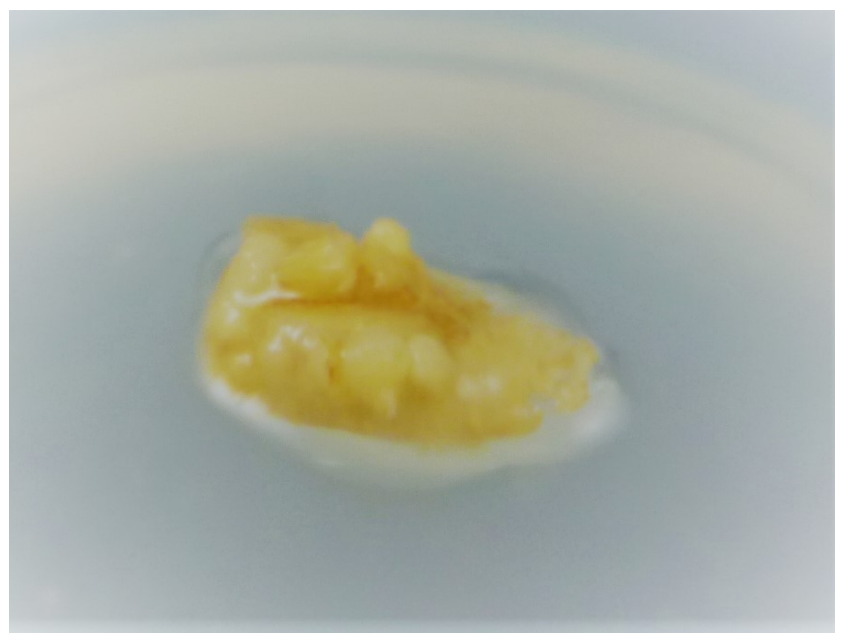

Figure 3. Explant formed somatic embryo

Table 1. The average level of survived explants based on the interaction between the type of media and cryoprotectant (\%)

\begin{tabular}{|c|c|c|c|c|c|c|c|c|c|c|c|c|c|c|c|c|}
\hline \multirow{2}{*}{ Medium } & \multicolumn{16}{|c|}{ Cryoprotectant $\square$} \\
\hline & \multicolumn{4}{|c|}{10 Minutes } & \multicolumn{4}{|c|}{20 Minutes } & \multicolumn{4}{|c|}{30 Minutes } & \multicolumn{4}{|c|}{40 Minutes } \\
\hline BA 1 ppm & 0.00 & \pm & 0.00 & $\mathrm{f}$ & 0.50 & \pm & 1.08 & def & 0.50 & \pm & 1.08 & def & 0.00 & \pm & 0.00 & $\mathrm{f}$ \\
\hline BA 2 ppm & 1.10 & \pm & 1.29 & bcde & 1.70 & \pm & 0.95 & abc & 1.10 & \pm & 1.29 & bcde & 0.00 & \pm & 0.00 & $\mathrm{f}$ \\
\hline BA 3 ppm & 0.80 & \pm & 1.32 & cdef & 0.90 & \pm & 1.10 & bcdef & 1.00 & \pm & 1.33 & bcdef & 0.00 & \pm & 0.00 & $\mathrm{f}$ \\
\hline BA 4 ppm & 0.50 & \pm & 1.08 & def & 2.10 & \pm & 0.99 & $\mathbf{a}$ & 1.00 & \pm & 1.15 & bcde & 0.00 & \pm & 0.00 & $\mathrm{f}$ \\
\hline NAA 1 ppm & 0.40 & \pm & 0.97 & ef & 0.80 & \pm & 1.32 & cdef & 0.00 & \pm & 0.00 & $\mathrm{f}$ & 0.00 & \pm & 0.00 & $\mathrm{f}$ \\
\hline NAA 2 ppm & 2.10 & \pm & 0.99 & $\mathbf{a}$ & 1.40 & \pm & 1.35 & abcd & 0.50 & \pm & 1.08 & def & 0.00 & \pm & 0.00 & $\mathrm{f}$ \\
\hline NAA 3 ppm & 1.60 & \pm & 1.07 & $a b c$ & 1.50 & \pm & 1.27 & $a b c$ & 1.80 & \pm & 0.92 & $\mathrm{ab}$ & 0.00 & \pm & 0.00 & $\mathrm{f}$ \\
\hline NAA 4 ppm & 1.00 & \pm & 1.33 & bcdef & 2.20 & \pm & 0.92 & $\mathbf{a}$ & 1.60 & \pm & 1.07 & $a b c$ & 0.00 & \pm & 0.00 & $\mathrm{f}$ \\
\hline
\end{tabular}

Note: different letters in columns indicate significant differences in the level of $5 \%$

Table 2. The average level of contaminated explants based on the interaction between the type of media and cryoprotectant (\%)

\begin{tabular}{|c|c|c|c|c|c|c|c|c|c|c|c|c|c|c|c|c|}
\hline \multirow{2}{*}{ Medium } & \multicolumn{16}{|c|}{ Cryoprotectant $\square$} \\
\hline & \multicolumn{4}{|c|}{10 Minutes } & \multicolumn{4}{|c|}{20 Minutes } & \multicolumn{4}{|c|}{30 Minutes } & \multicolumn{4}{|c|}{40 Minutes } \\
\hline BA 1 ppm & 3.00 & \pm & 0.00 & $\mathrm{a}$ & 2.50 & \pm & 1.08 & abc & 2.50 & \pm & 1.08 & $a b c$ & 3.00 & \pm & 0.00 & $\mathrm{a}$ \\
\hline BA 2 ppm & 1.90 & \pm & 1.29 & bcde & 1.30 & \pm & 0.95 & de & 1.90 & \pm & 1.29 & bcde & 3.00 & \pm & 0.00 & $\mathrm{a}$ \\
\hline BA 3 ppm & 2.20 & \pm & 1.32 & abcd & 2.10 & \pm & 1.10 & abcd & 2.00 & \pm & 1.33 & abcd & 3.00 & \pm & 0.00 & $\mathrm{a}$ \\
\hline BA 4 ppm & 2.50 & \pm & 1.08 & $a b c$ & 0.90 & \pm & 0.99 & e & 2.00 & \pm & 1.15 & abcd & 3.00 & \pm & 0.00 & $\mathrm{a}$ \\
\hline NAA 1 ppm & 2.60 & \pm & 0.97 & $\mathrm{ab}$ & 2.20 & \pm & 1.32 & abcd & 3.00 & \pm & 0.00 & $\mathrm{a}$ & 3.00 & \pm & 0.00 & $\mathrm{a}$ \\
\hline NAA 2 ppm & 0.90 & \pm & 0.99 & e & 1.60 & \pm & 1.35 & bcde & 2.50 & \pm & 1.08 & $a b c$ & 3.00 & \pm & 0.00 & $\mathrm{a}$ \\
\hline NAA 3 ppm & 1.40 & \pm & 1.07 & de & 1.50 & \pm & 1.27 & cde & 1.20 & \pm & 0.92 & de & 3.00 & \pm & 0.00 & $\mathrm{a}$ \\
\hline NAA 4 ppm & 2.00 & \pm & 1.33 & abcd & 2.00 & \pm & 1.05 & abcd & 1.40 & \pm & 1.07 & de & 3.00 & \pm & 0.00 & $\mathrm{a}$ \\
\hline
\end{tabular}

Note: different letters in columns indicate significant differences in the level of $5 \%$ 


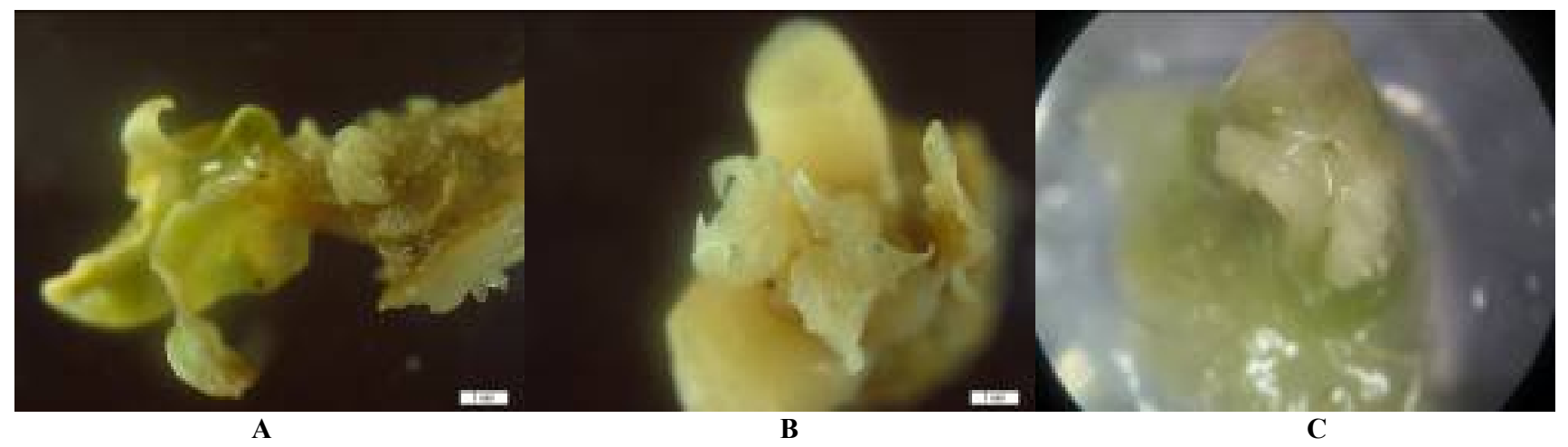

Figure 4. The formation of in vitro callus derived from lateral shoot of papaya (A, B, C) with immersion of explants on cryoprotectant for 20 minutes and planted on MS medium supplemented with 2 ppm NAA, observed using microscope with an enlarged binocular electric microscope $10 \times 10$ brand Olympus type CX23 (Bar: $1 \mathrm{~mm}$ )

\section{Discussion}

Cryopreservation using liquid nitrogen with a temperature of $-196^{\circ} \mathrm{c}$ make the cells are in an inactive state, where cell division and metabolic processes in cells, tissues or organs that are stored can be stopped so that the plant material can be stored without changes within an indefinite period. Some tissue is often used is the apical meristem and lateral organs of plants (embryo, endosperm, ovule, anthers/pollen), seeds, cell culture, somatic embryos, protoplasts, callus, and so on. The results of the whole study showed that the growth ability of papaya lateral shoots to produce somatic embryos after being stored in liquid nitrogen is still low after it was stored in the liquid nitrogen. This is presumably because explants must recover first after being stored in liquid nitrogen, and explants must be able to reissue a cryoprotectant that goes into plant cells because cryoprotectant remaining in the plant cells can poison and damage cells.

One of the survived explants was being able to form a somatic embryo, and the other explants form a callus. Somatic embryos papaya that derived from papaya lateral shoots has a characteristic i.e., compact, opaque, and the growth is relatively slow with complex structure after grown on MS medium. Callus is observed only in cases where the technique is not optimized. The meristematic zone of apices, from which organized growth originates, is composed of a relatively homogeneous population of small, actively dividing cells, with few small vacuoles and a high nucleo-cytoplasmic ratio (Engelmann 2004). Some of explants that are not capable of growing allegedly damaged cells. During freezing and melting, plant cells can be damaged due to: (i) the adaptation from a very low temperature, (ii) the formation of ice crystals, (iii) dehydration, and (iv) the formation of free radicals. During the cooling process, lipids in the membrane will undergo a phase transition from the liquid crystal into a gel phase. This process resulted in cell leakage, so cells become damage, since not all the lipid has phase transition at the same temperature. At low temperatures, some proteins in plant cells will be inactive due to the nature of the protein which is sensitive to low temperatures (Reinhoud et al. 2000).
Results of the survived explants are better on the immersion with cryoprotectant for 10 and 20 minutes. Explants that are immersed too long in cryoprotectant are not able to grow, and many of them are contaminated. This is presumably because long-term cryoprotectant immersion can damage and poison cells. Cryoprotectant can poison plant cells when it is used at high concentrations or in elevated temperatures (Reinhoud et al. 2000).

While the addition of plant growth regulators such as BA and NAA had no response to the explant growth, whereas BA and NAA are expected to affect the metabolism in the tissue explants. Lestari (2011) explains that the use of plant growth regulators in plant tissue culture is very important to control organogenesis and morphogenesis in the formation and development of shoots, roots and callus formation. There are two classes of plant growth regulators that are often used in tissue culture, namely cytokinin and auxin. Among the cytokine groups are including BA (benzyl adenine), kinetin (furfuryl amino purine), 2-Ip (dimethylallyl amino purine), and zeatin while the auxin group are IAA (indole acetic acid), NAA (naphthalene acetic acid), IBA (indole butyric acid), 2.4-D (2.4-dichlorophenoxy acetic acid), dicamba (3,6-dichloroo-anisic acid), and picloram (4-amino-3,5,6tricloropicolinic acid). Research from Kasutjianingati and Boer (2013) showed that the application of BAP and NAA can increase the multiplication of in vitro banana shoots.

The used of lateral shoots as explants were rarely done by researchers because of the difficulty of sterilization of explants. Sterilization is difficult because almost all parts of papaya produce a white liquid called sap. El Muossaoui et al. (2001) explains that the largest component of papaya sap is water $(85 \%)$, the rest consists of carbohydrate, salt, fat, biomolecules (glutathione and cysteine protease) and other proteins. Papaya sap also contains enzymes, including papain, kimopapain, and lysosomes. Some researchers used many shoot tips as explants (Azimi et al. 2005; Wang et al. 2005; Silva 2014) because the shoot tips no sap content and the effective way to establish in vitro cultures for papaya is initially from seeds (Silva 2014) but of course, the genetic germplasm stored papaya from shoot 
tips and seeds are not the same as the parent, but it is the combination for more than $50 \%$ pollinate of the papaya is a cross-pollination. Engelmann (2000) also explains that explants are often difficult to regenerate after passing through the cryopreservation process due to the complexity of the tissue composition resulting in much difference in sensitivity to drying and freezing.

The condition of the cell contents in Figure 1 showed the different conditions due to the immersion treatment with cryoprotectants. The reduction of cell contents characterized by the reduction of green chloroplasts from cell fluid, which was replaced with cryoprotectant solution. The cryoprotectant solution will keep the cell during the freezing process by increasing the concentration of the solution and preventing the formation of ice crystals by performing dehydration or drying stages (Simione 1998). The function of cryoprotectants is to change some water properties such as lowering the freezing point of water and reaching the transition point before the occurrence of nucleation of ice within the cell due to cellular conditions, the transition point can be reached at about $-100^{\circ} \mathrm{C}$ while the ice crystals are formed before the temperature is reached (Reinhoud et al. 2000).

The existence of storage with liquid nitrogen with very low temperatures, makes the cell membrane must work hard to protect the contents of the cells. The cell membrane is the outermost part of cells that separates the intracellular components and the environment outside the cell. The main tasks of cell membranes include forming a permeable barrier. Cell membrane protection mechanisms include; (i) increased hydration of phospholipids in the polar head group on the surface of the plasma membrane, (ii) the accumulation of compatible osmolites such as soluble carbohydrates, (iii) anti-freeze protein accumulation in the apoplastic space, and (iv) changes in the reticulum endoplasm (Fujikawa dan Jitsuyama 2000).

Based on research results, it can be concluded that the ability of papaya lateral shoots to produce somatic embryos after being stored in liquid nitrogen is still low because of the difficulty of sterilizing the lateral shoots as an explant and the ability to recover less. Cryopreservation of lateral shoots that are immersed in cryoprotectant for 10 and 20 minutes gave survival of explants more better and the addition of the plant growth regulator on medium has not yet influence on the growth of papaya lateral shoots.

\section{ACKNOWLEDGEMENTS}

The author thanks the Bogor Agricultural University, BPP-DN DIKTI and Andalas University, Padang, Indonesia for support in this research.

\section{REFERENCES}

Azimi M, Brien CO, Ashmore S, Drew R. 2005. Cryopreservation of papaya germplasm. Acta Hort 692, ISHS 2005: 43-50. $\square$

El Muossaoui A, Nijs M, Paul C, Wintjen R, Viscentelli J, Azarkan M, Loose Y. 2001. Review Revisiting the Enzyme Storage in the Laticifier of Carica papaya in The context of their possible participation in the plant defense mechanism. Cell Mol Life Sci. 58: 556-570. $\square$

Engelmann F. 2000. Importance of cryopreservation for the conservation of plant genetic resources. JIRCAS Intl Agric Ser 8: 8-16.

Engelmann F. 2004. Plant cryopreservation: Progress and Prospects. In Vitro Cell Dev Bio Plant 40: 427-433.

Fang JY, Wetten A, Hadley P. 2004. Cryopreservation of cacao (Theobroma cacao L.) somatic embryos for long-term germplasm storage. Plant Sci 66: 669-675.

Fujikawa S, Jitsuyama Y. 2000. Ultrastructural aspects of freezing adaptation of cells by vitrification. JIRCAS Intl Agric Ser 8: 36-42.

Sobir. 2009. Sukses Bertanam Pepaya Unggul. Agromedia Pustaka, Jakarta. [Indonesian]

Kasutjianingati , Boer D. 2013. In-vitro Micropropagation of banana cv Mas Kirana (Musa acuminate L) utilizing BAP and NAA. Agroteknos 3 (1): 60-64.

Lestari EG. 2011. The role of growth regulator in tissue culture plant propagation. Agrobiogen 7 (1): 63-68.

Oktaviani L. 2012. Pengujian Sifat Benih Pepaya (Carica papaya L.) dengan Perlakuan Penyimpanan Suhu Rendah. [Hon. Thesis]. Bogor Agricultural University, Bogor. [Indonesian]

Reinhoud PJ, Iren FV, Kijne JW. 2000. Cryopreservation of undifferentiated plant cells. JIRCAS Intl Agric Ser 8: 91-102.

Sakai A, Kobayashi S, Oiyama I. 1991. Cryopreservation of nucellar cells of navel orange (Citrus sinensis Osb.) by a simple freezing method. Plant Sci 74:243-248.

Silva JAT. 2014. Callus induction in papaya (Carica papaya L.) and synseed production for low-temperature storage and cryopreservation. Folia Hort 26 (2): 155-162.

Simione FP. 1998. Cryopreservation manual. Nalge Nunc International.

Wang YL, Fan MJ, Liaw SL. 2005. Cryopreservation of in vitro-grown shoot tips of papaya (Carica papaya L.) by vitrification. Bot Bull Acad Sin 46: 29-34. 